7. Nevodovskyi Ye.P., Vid'Machenko A.P., Morozhenko O.V., Nevodovskyi P.V., Syniavskyi I.I. The Ukrainian Youth Satellite: investigation of the Earth's aerosol stratum with the use of UV-polarimeter. Kosmichna Nauka I Tekhnologiya (ISSN 1561-8889). 2004. V. 10. No. 5/6. P. 27-32.

8. Ozone: Space Vision (Space monitoring of Earth Atmospheric Ozone) Copyright By Dr. Fred Ortenberg, ASRI, Technion November 2002. P. 17-18.

9. Nevodovsky P., Morozhenko A., Vidmachenko A., Geraimchuk M., Zbrutskyi A., Kureniov Yu., Sergunin V., Hirniak Yu., Ivakhiv O. Ultraviolet Polarimeter for Studying the Aerosol Component in the Earth Atmosphere. In Abstracts (Proceedings) of International Symposium "Atmospheric Radiation and Dynamics", Publishing Company. St Petersburg. Russia. 2013. P. 218.

10. Nevodovskyi P., Morozhenko O., Vidmachenko A., Ivakhiv O., Geraimchuk M., Zbrutskyi O. Tiny Ultraviolet Polarimeter for Earth Stratosphere from Space Investigation. Proceedings of $8^{\text {th }}$ IEEE International Conference on Intelligent Data Acquisition and Advanced Computing Systems: Technology and Applications (IDAACS'2015) Warsaw. Poland. Sept. 24-26. 2015. V.1. P. 2832.

11. Nevodovskyi P.V., Morozhenko A.V. Studies into stratospheric ozone layer from near-earth orbit utilizing ultraviolet polarimeter. In Acta Astronautica. 2009. V. 69. No 1. P. 54-58.

12. Travis L. Earth Observing Scanning Polarimetr. Long-Term monitoring of Global climate forcings and Feedbacks, Ed. by J. Hansen, W. Rossow, I. Fung. New York. 1992. P.40-46.

13. M. Geraimchuk, O. Genkin, O. Ivakhiv, Yu. Kureniov, O. Morozhenko, P. Nevodovskyi, S. Petrenko. Elements and Systems of Polarization Devices for Aerospace Investigation. Monography, EKMO. Kyiv (in Ukrainian). 2009.

14. Мороженко О.В. Методи i результати дистанційного зондування планетних атмосфер. Київ : Наукова думка, 2004. $647 \mathrm{c}$.

15. Неводовский П.В., Мороженко А.В., Неводовский Е.П., Гераимчук М.Д. Изучение характеристик аэрозоля стратосферы Земли методом ультрафиолетовой поляриметрии. Оптика и спектроскопия. 2009. 107. № 2. С. 231-23.

16. Мороженко О.В., Неводовський П.В., Видьмаченко А.П., Гераїмчук М.Д., Івахів О.В., Делець О.С. Про застосування ультрафіолетової поляриметрії для супутниковихдосліджень стратосферного аерозолю Землі. Украӥнський метрологічний журнал. 2014. № 2. C. 27-32.

Надійшла до редколегії 01.08.2018 p.

УДК 532.516

\title{
ЧИСЛЕННОЕ МОДЕЛИРОВАНИЕ ВЗАИМОДЕЙСТВИЯ НЕДОРАСШИРЕННОЙ СВЕРХЗВУКОВОЙ СТРУИ ГАЗА С ПЛОСКОЙ ПРЕГРАДОЙ
}

\author{
С.А. Николин, А.А. Приходько
}

Днепровский нащиональный университет имени Олеся Гончара, пр. Гагарина, 72, г. Днепр, 49010, Украина, е-mail: sergeynikolin@gmail.com

\begin{abstract}
Наведено результати чисельного моделювання на основі нестаціонарних усереднених за Рейнольдсом рівнянь Нав'є - Стокса взаємодії недорозширеного надзвукового струменя газу 3 плоскою пластиною, яка встановлювалася на різних відстанях від зрізу сопла. Результати розрахунків представлено у вигляді розподілів числа Маха і градіснта щільності в розрахунковій області, а також коефіціснтів тиску і тертя по поверхні пластини. Виконано порівняння результатів числових розрахунків з експериментальними даними.

Ключові слова: надзвуковий струмінь, плоска пластина, стрибок ущільнення, рециркуляційна зона.
\end{abstract}

The results of numerical modeling based on the nonstationary Reynolds-averaged Navier - Stokes 
equations for the interaction of an underexpanded supersonic gas jet with a flat obstacle, which was established at different distances from the nozzle exit section are presented. The results of the calculations are presented in the form of the distribution of the Mach number and the density gradient in the calculated region, and the pressure and friction coefficients over the surface of the plate. The results of the numerical calculation are compared with the experimental data.

Keywords: supersonic jet, flat barrier, shock wave, recirculation zone.

Приведены результаты численного моделирования на основе нестационарных осредненных по Рейнольдсу уравнений Навье - Стокса взаимодействия недорасширенной сверхзвуковой струи газа с плоской преградой, которая устанавливалась на разных расстояниях от среза сопла. Результаты расчетов представлены в виде распределения числа Маха и градиента плотности в расчетной области, а также коэффициентов давления и трения по поверхности пластины. Выполнено сравнение результатов численного счета с экспериментальными данными.

Ключевые слова: сверхзвуковая струя, плоская преграда, скачок уплотнения, рециркуляционная зона.

\begin{tabular}{lrr}
\multicolumn{2}{c}{ Введение. } & При \\
космических проектировании \\
важным летательных \\
моделирование
\end{tabular} процессов в моменты его старта и посадки (в случае возвращаемых ступеней либо межпланетарного полета). В зависимости от расстояния между выходным сечением сопла и преградой возникают сложные трехмерные турбулентные течения, которые сопровождаются скачками уплотнения, волнами разряжения и контактными разрывами. Проблематике изучения струйных течений и их взаимодействию с преградами посвящено большое количество теоретических и экспериментальных работ [1-7].

Множественные теоретические исследования $[2 ; 4 ; 5 ; 8]$ направлены на моделирование турбулентных струй и изучение их взаимодействия с плоскими преградами при изменении числа Маха, расстояния до преграды, угла наклона преграды и т.д.

В работе [2] приведены результаты численного исследования нестационарного течения у преграды, которые потом сравнивались с экспериментальными данными. Получена картина течения у преграды, дано представление об интенсивности колебаний и скорости возвратного течения.

Результаты стационарного численного расчета взаимодействия струи с преградой приведены в работе [5]. Исследуются как перерасширенные, так и недорасширенные струи при различных степенях нерасчетности. Полученные численные решения дают подробную информацию о картине течения во всей области.

В работе [8] численно изучаются различные режимы взаимодействия сверхзвуковой недорасширенной струи как с конечной, так и безграничной преградой. Представлены частотные спектры колебаний давления в центре преграды.

Результаты численного исследования взаимодействия недорасширенной струи с плоской преградой приведены в работе [1]. Выполнен сравнительный анализ моделей турбулентности SpalartAllmaras (SA) и Shear-Stress Transport (SST) применительно к рассматриваемой задаче. При сравнении с экспериментальными данными обе модели турбулентности показали схожие результаты.

Во всех вышеуказанных работах приведенные результаты расчетов удовлетворительно совпадают с экспериментальными данными. Но этот хороший результат получен лишь для конкретных случаев, так как они все решались с использованием методов первого порядка, на сетках низкого качества разрешения.

С другой стороны, для более полного понимания всех происходящих процессов в зоне взаимодействия струи с преградой существуют экспериментальные исследования, на результаты которых часто ссылаются при проведении теоретических исследований $[1 ; 6 ; 7]$. Но получение экспериментальных данных требует значительных временных и ресурсных затрат. Поэтому, со стремительным развитием вычислитель-ной техники, для 
уменьшения этих затрат перспективным направлением является использование компьютерного модели-рования.

В настоящей работе результаты численного моделирования натекания сверхзвуковой струи газа на преграду сравниваются с результатами экспериментальных исследований [4]. Также приводятся дополнительные данные, которые было невозможно получить, либо по соображениям автора они не были приведены. Это позволяет лучше понимать особенности газодинамических процессов при взаимодействии нерасчетных струй с преградой.

Физическая постановка задачи. Рассматривается задача расчета натекания сверхзвуковой недорасширенной струи газа на плоскую пластину, которая расположена перпендикулярно к оси симметрии сопла. Геометрия сопла и определяющие параметры были выбраны в соответствии с работой [4]. Сопло имеет коническую форму с углом полураствора $\varphi=9^{\circ}$. Число Маха на срезе сопла $M_{a}=2$. Отношение давления на срезе сопла $p_{a}$ к окружающему выдерживалось равным $n \approx 2.85$. Давление торможения в форкамере $p_{0} \approx 10$ ата, a статическое давление в окружающем пространстве $p_{\infty} \approx 0.43$ ата. Температура торможения в камере принята равной $300{ }^{\circ} \mathrm{K}$, а в окружающей среде - $288{ }^{\circ} \mathrm{K}$. Расчеты проведены для случаев, когда $l / r_{a}$ равно 2 , 4 и 6 , где $l$ - расстояния от среза сопла до преграды, $r_{a}$ - радиус выходного сечения сопла (рис. 1). Настоящая задача является осесимметричной, что позволяет проводить численное моделирование как в двухмерной осесимметричной, так и трехмерной постановке. Размеры расчетной области выбраны таким образом, чтобы граничные условия не влияли на параметры потока в ядре струи.

\section{Математическая}

постановка

задачи. Для математического описания процессов, происходящих во время взаимодействия сверхзвуковой струи газа с преградой, используется система уравнений Навье - Стокса, выражающая законы сохранения массы, импульса и энергии для идеального газа.

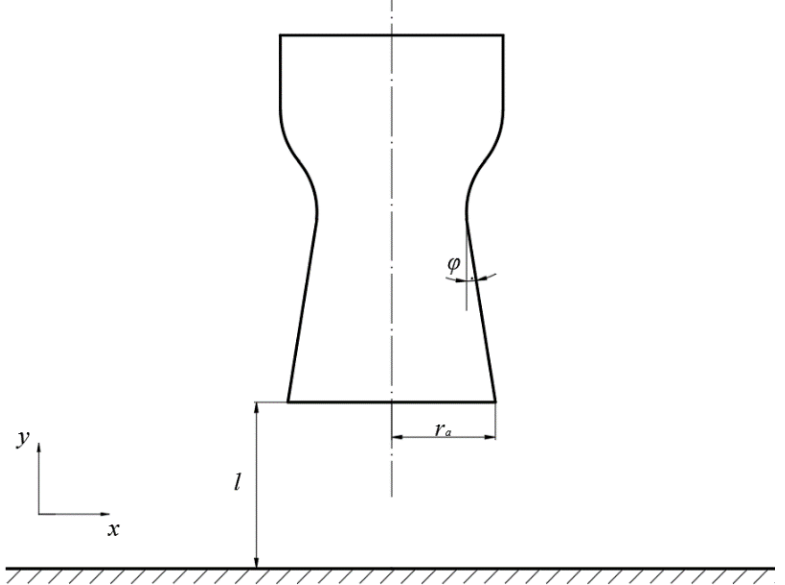

Рис. 1. Геометрия расчетной модели

В декартовой системе координат эти уравнения имеют следующий вид:

- уравнение неразрывности:

$$
\frac{\partial \rho}{\partial t}+\frac{\partial}{\partial x_{i}}\left[\rho u_{i}\right]=0 ;
$$

- уравнение движения:

$$
\frac{\partial\left(\rho u_{i}\right)}{\partial t}+\frac{\partial}{\partial x_{j}}\left[\rho u_{i} u_{j}+p \delta_{i j}-\tau_{i j}^{*}\right]=0 ;
$$

- уравнение баланса энергии:

$$
\frac{\partial(\rho E)}{\partial t}+\frac{\partial}{\partial x_{j}}\left[\rho u_{j} E+u_{j} p+q_{j}^{*}-u_{i} \tau_{i j}^{*}\right]=0 ;
$$

- уравнение состояния идеального газа:

$$
p=\rho R T,
$$

где

$$
\begin{gathered}
\tau_{i j}^{*}=\mu\left(\frac{\partial u_{i}}{\partial x_{j}}+\frac{\partial u_{j}}{\partial x_{i}}\right)-\frac{2}{3} \mu \frac{\partial u_{k}}{\partial x_{k}} \delta_{i j}-\rho u_{i}^{\prime \prime} u_{j}^{\prime \prime} ; \\
q_{j}^{*}=q_{j}+C_{p} \rho T u_{j}^{\prime \prime}=-C_{p} \frac{\mu}{\operatorname{Pr}} \frac{\partial T}{\partial x_{j}}-C_{p} \frac{\mu_{t}}{\operatorname{Pr}_{t}} \frac{\partial T}{\partial x_{j}} .
\end{gathered}
$$

Вышеприведенная система уравнений является незамкнутой, поскольку в нее входит неизвестный тензор рейнольдсовых напряжений. Для еe замыкания используются модели турбулентности. В настоящей работе применена модель турбулентности SST k- $\omega$. Эта модель хорошо зарекомендовала себя при расчете струйных течений [1].

В начальный момент времени по всей расчетной области задаются параметры окружающей среды. Для случая покоящейся окружающей среды скорость, кинетическая энергия турбулентности и удельная диссипация кинетической энергии турбулентности равны нулю $u_{x}=0, u_{y}=0, u_{z}=0, k=0, \omega=0$. Давление 
и температура равны значениям окружающей среды $\quad p=p_{\infty}, \quad T=T_{\infty}$, плотность среды вычисляется из уравнения состояния.

Во входном сечении сопла параметры потока определялись через параметры торможения $p=p_{0}, T=T_{0}$.

На непроницаемых стенках (границы сопла и пластина) задавались условия прилипания и тепловой изоляции.

На выходных границах задавалось статическое давление.

Задача решалась численно с помощью метода контрольных объемов, который реализован в пакете прикладных программ. Ранее вычислительный алгоритм был протестирован на задаче внешнего обтекания цилиндра и аэродинамических профилей при дозвуковых и сверхзвуковых скоростях потока. Полученные результаты расчетов удовлетворительно совпадали с экспериментальными данными.

Результаты и обсуждение. Ниже приведены некоторые результаты численных расчетов газодинамических параметров как в самом потоке, так и у преграды, которые сравниваются с экспериментальными данными.

Сперва рассмотрены режимы с расстоянием от среза сопла до преграды $l=2 R$ (рис. 2) и $l=4 R$ (рис. 3). Максимум давления находится в центре пластины (на оси симметрии) и газ, проходя через формирующийся вблизи преграды скачок уплотнения, растекается от центра к периферии под действием лишь градиента давления. На рис. 2в и 3в приведено сравнение распределений давления по преграде, полученных экспериментально и численно.

Анализируя распределение параметров, можно сделать вывод, что результаты численного расчета хорошо коррелируют с экспериментальными данными как количественно, так и качественно. Но при этом во втором случае с увеличением периферийного расстояния появляются некоторые отклонения, которые могут быть вызваны инерционностью измеряемой аппаратуры при проведении эксперимента либо шероховатостью пластины, которая в численном моделировании не учитывалась.

Скачок уплотнения, который образуется на некотором расстоянии от преграды, имеет дугообразную форму. Максимум числа Маха в первом случае реализуется в области висячего скачка, а во втором - в области висячего и прямого скачка. Поток газа после полного торможения разгоняется от дозвуковой скорости в окрестности оси струи до сверхзвуковой. Радиальная струя так же, как и осесимметричная нерасчетная струя, имеет «бочкообразную» структуру.

Распределение изобар позволяет оценить волновую структуру, которая возникает при взаимодействии недорасширенной струи с преградой.

Положительное значение коэффициента трения на пластине в области скачка (рис. 2д, 3д) показывает, что течение является безотрывным. Это подтверждает и картина линий тока в этой области (рис. 2е, 3e). Но вот дальше по периферии в первом случае (рис. 2д) возникает циркуляционное течение, что соответствует резкому скачку коэффициента трения до отрицательных значений.

Следующим рассмотренным случаем является расположение пластины от среза сопла на расстоянии $l=6 R$ (рис. 4). Этот режим течения является более сложным, чем первые два. В этом случае образуется сложная система скачков уплотнения с возникновением периферийного максимума давления не на оси симметрии, а на некотором расстоянии от нее (рис. 4в). Как и в предыдущих случаях, численные расчеты удовлетворительно согласуются с экспериментальными данными.

Как было отмечено в работах $[1 ; 5]$, периферийный максимум давления образуется из-за того, что при взаимодействии прямого и висячего скачков уплотнения образуется тройная конфигурация с косым скачком и контактной поверхностью, между которыми возникает область течения с достаточно большими скоростными напорами. Взаимодействие этой струи с 
преградой и образует давление, которое превышает давление за скачком $P_{02}$.

По аналогии с предыдущими случаями, отошедший от преграды прямой скачок уплотнения имеет небольшое искривление. Поток за ним от дозвукового

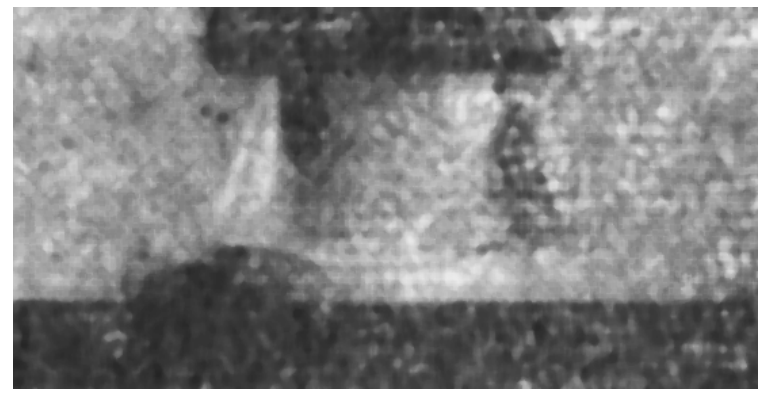

a
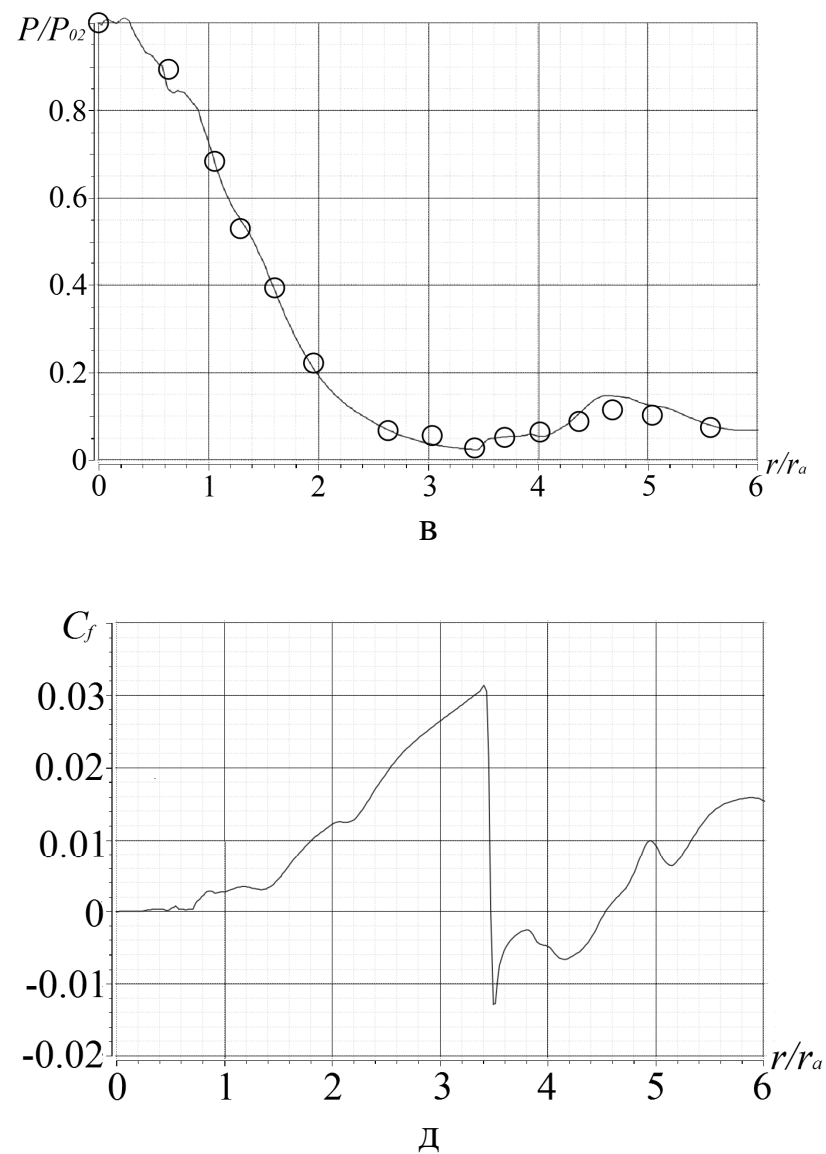

режима в центральной зоне переходит в сверхзвуковой режим далее по периферии с образованием «бочкообразной» структуры.

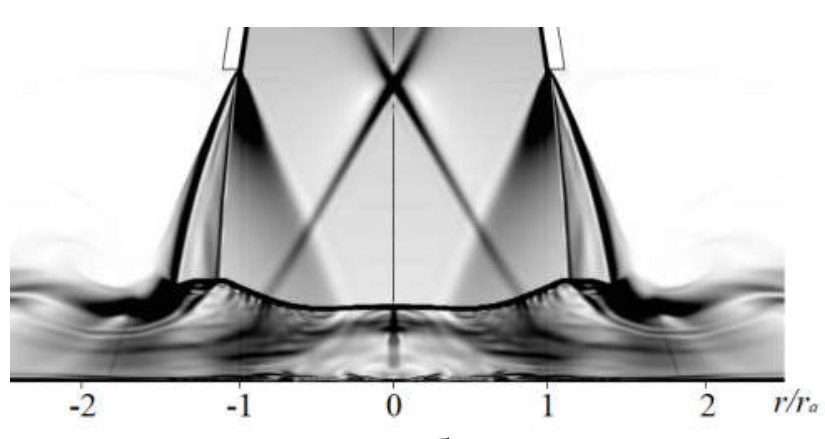

6
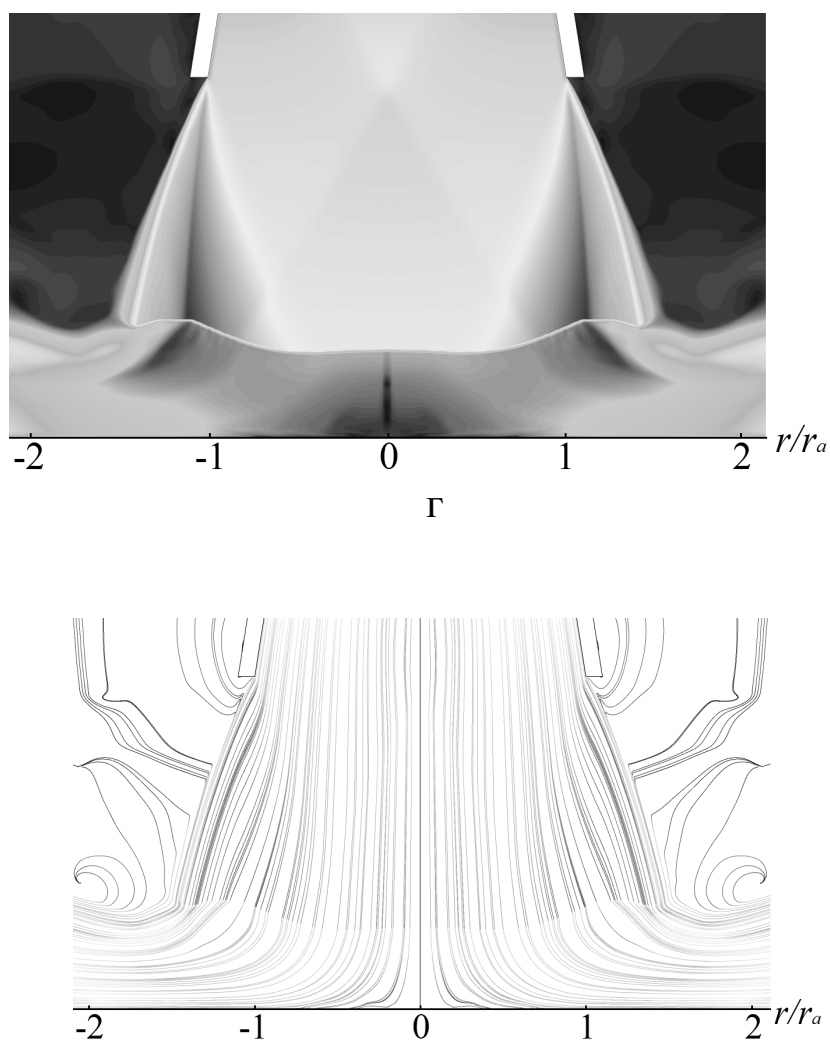

e

Рис. 2. Газодинамические параметры для случая $l=2 R$ :

a - экспериментальная визуализация (шлирен-фотография) картины течения; б - градиент плотности; в - коэффициент давления на пластине (сплошная линия - численный расчет, круги - эксперимент); г - числа Маха; д - коэффициент трения на пластине; е - линии тока 


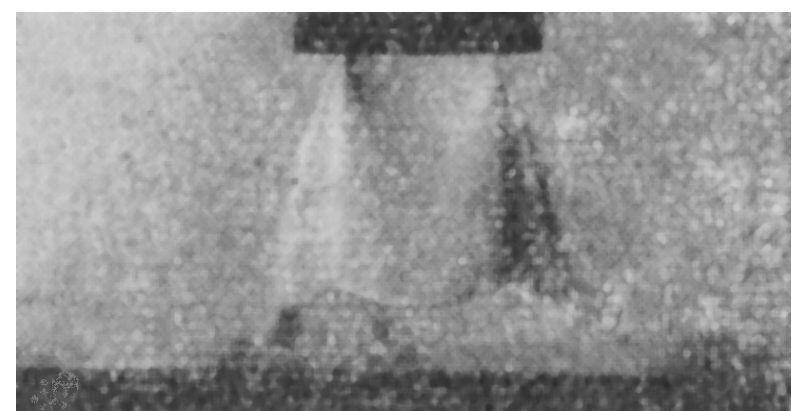

a
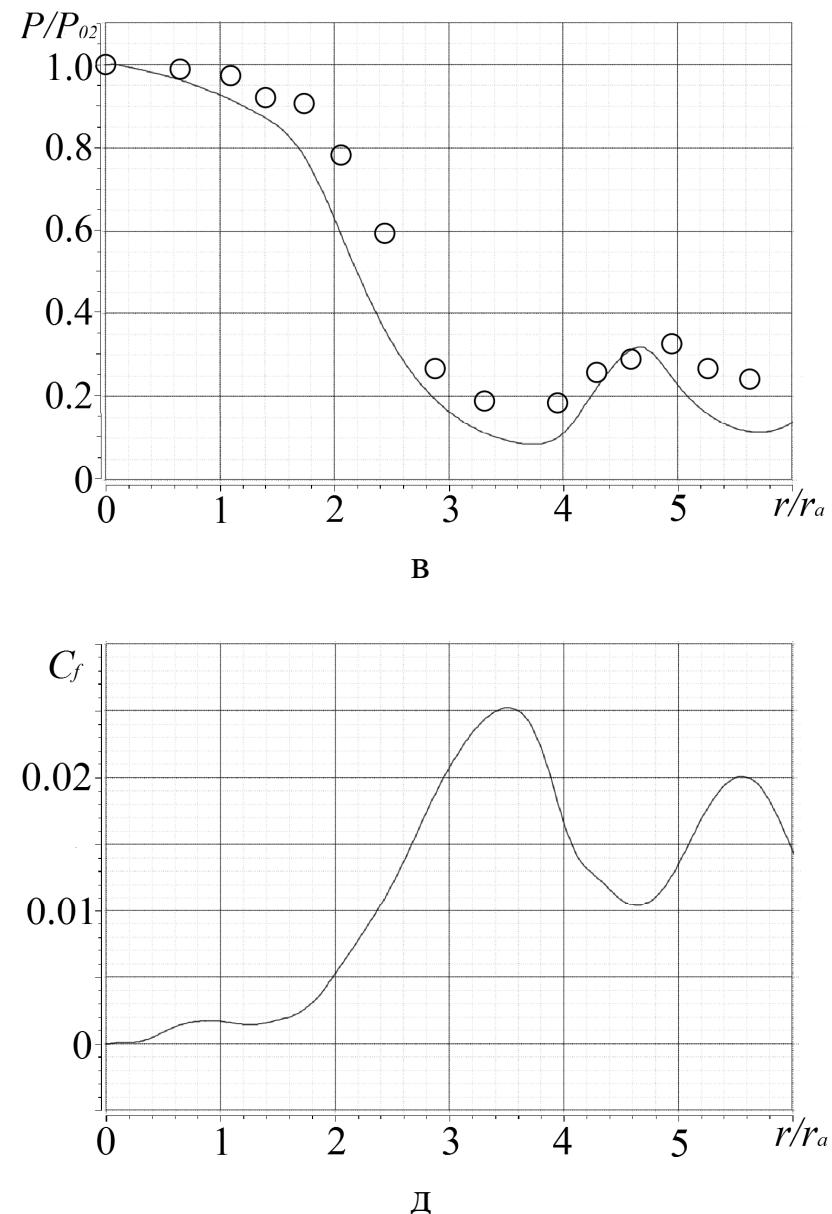
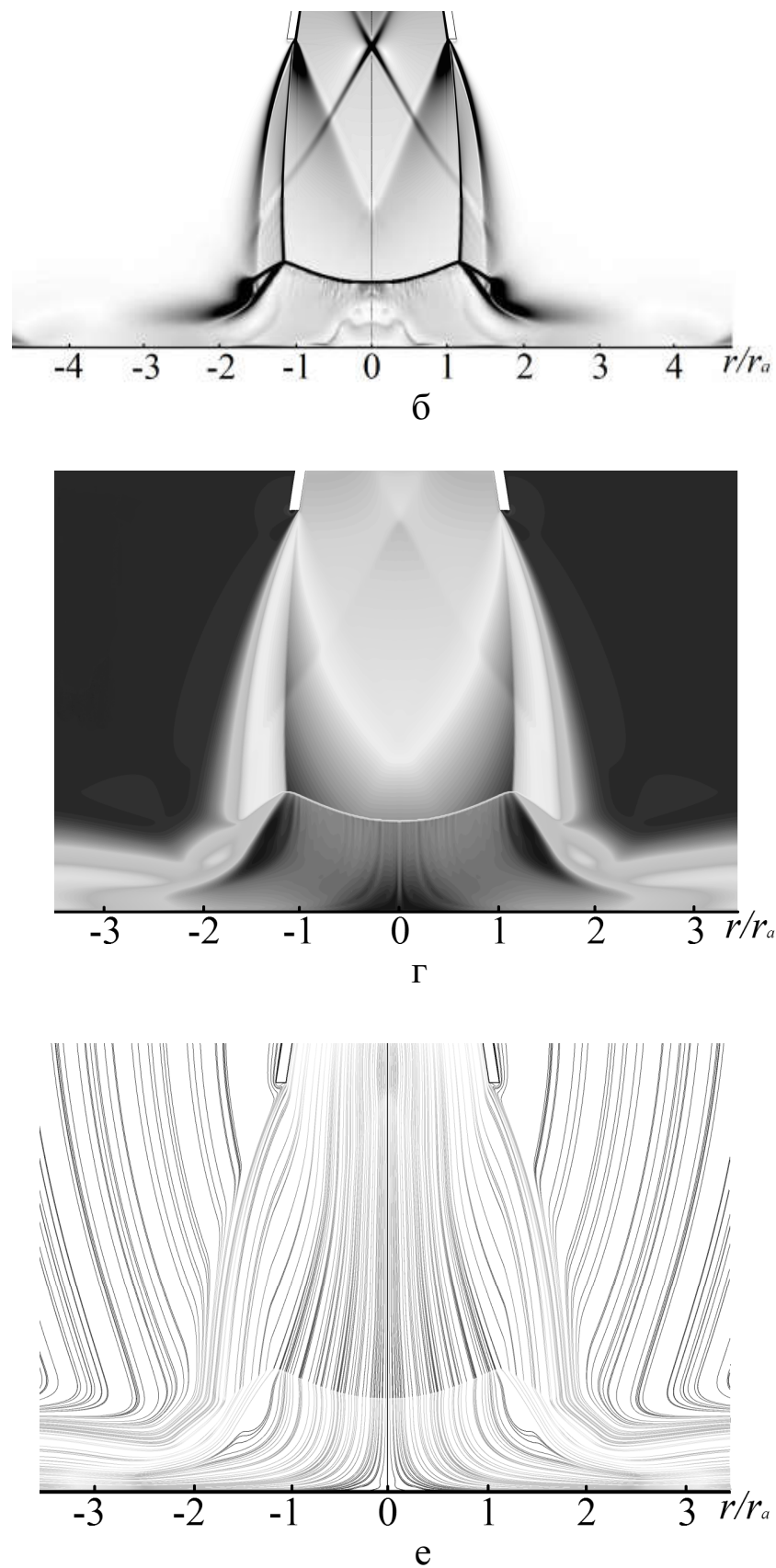

Рис. 3. Газодинамические параметры для случая $l=4 R$ :

a - экспериментальная визуализация (шлирен-фотография) картины течения; б - градиент плотности; в - коэффициент давления на пластине (сплошная линия - численный расчет, круги - эксперимент); г - числа Маха; д - коэффициент трения на пластине; е - линии тока

На рис. $4 \mathrm{e}$ четко видно циркуляционное возвратное отрывное течение, которое образуется за прямым скачком. Как и в первом случае, отрыв течения приводит к возникновению отрицательных значений коэффициента трения (рис. 4д).

Следует отметить, что процесс натекания высокоскоростного потока газа на преграду является нестационарным. Нестационарность сопровождается колебанием газодинамических характеристик в зоне взаимодействия струи с преградой. На рис. 5 представлены графики изменения давления в точке торможения. Колебания давления не имеют постоянного периода и амплитуды.

Выводы. Для численного моделирования взаимодействия недорасширенной сверхзвуковой струи газа с плоской преградой применены нестационарные осредненные по Рейнольдсу уравнения Навье - Стокса. 


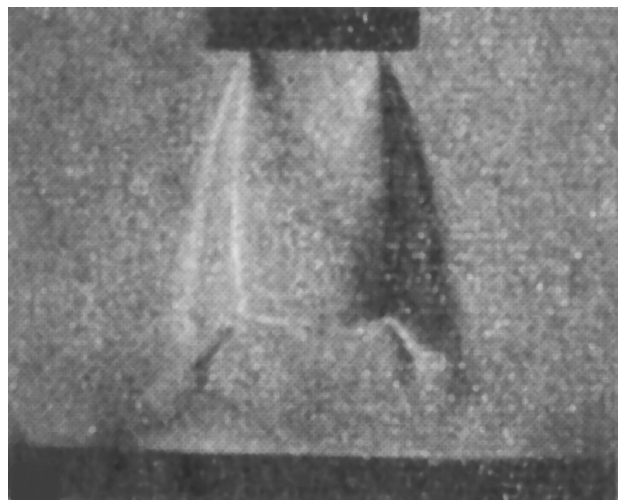

a
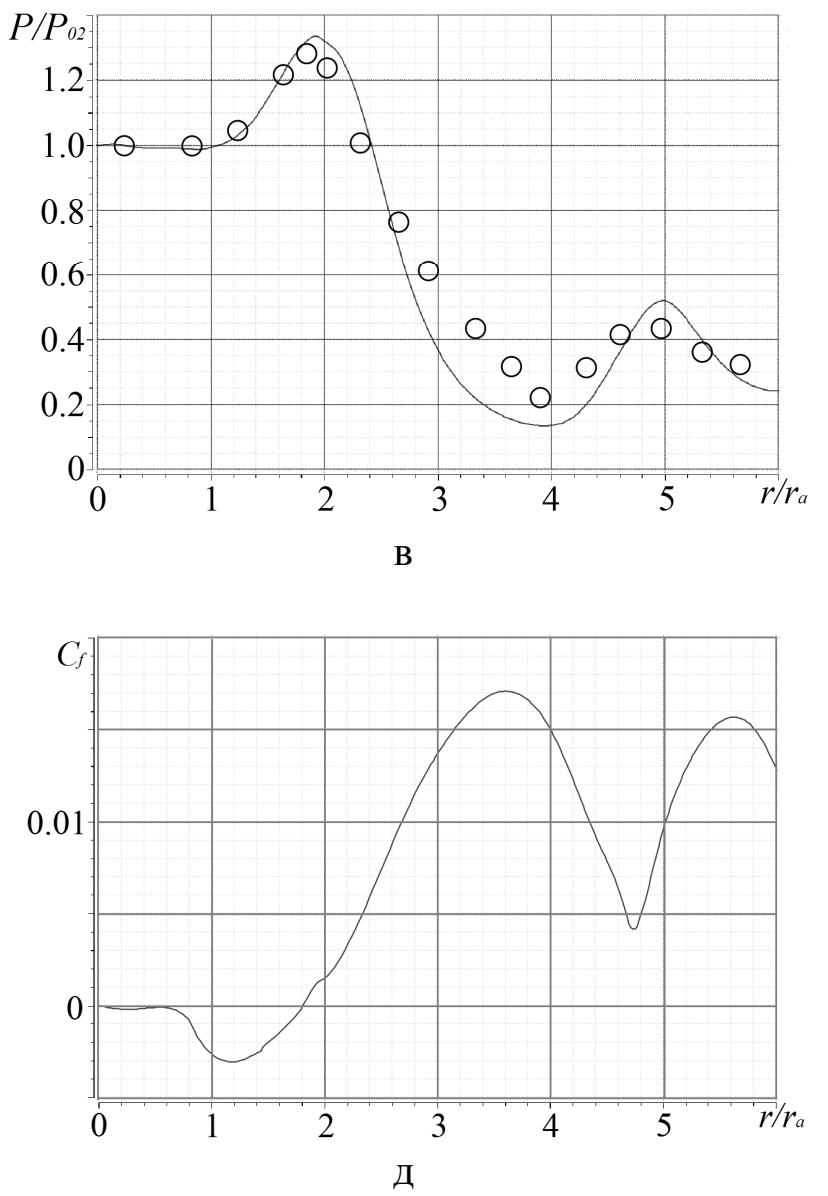
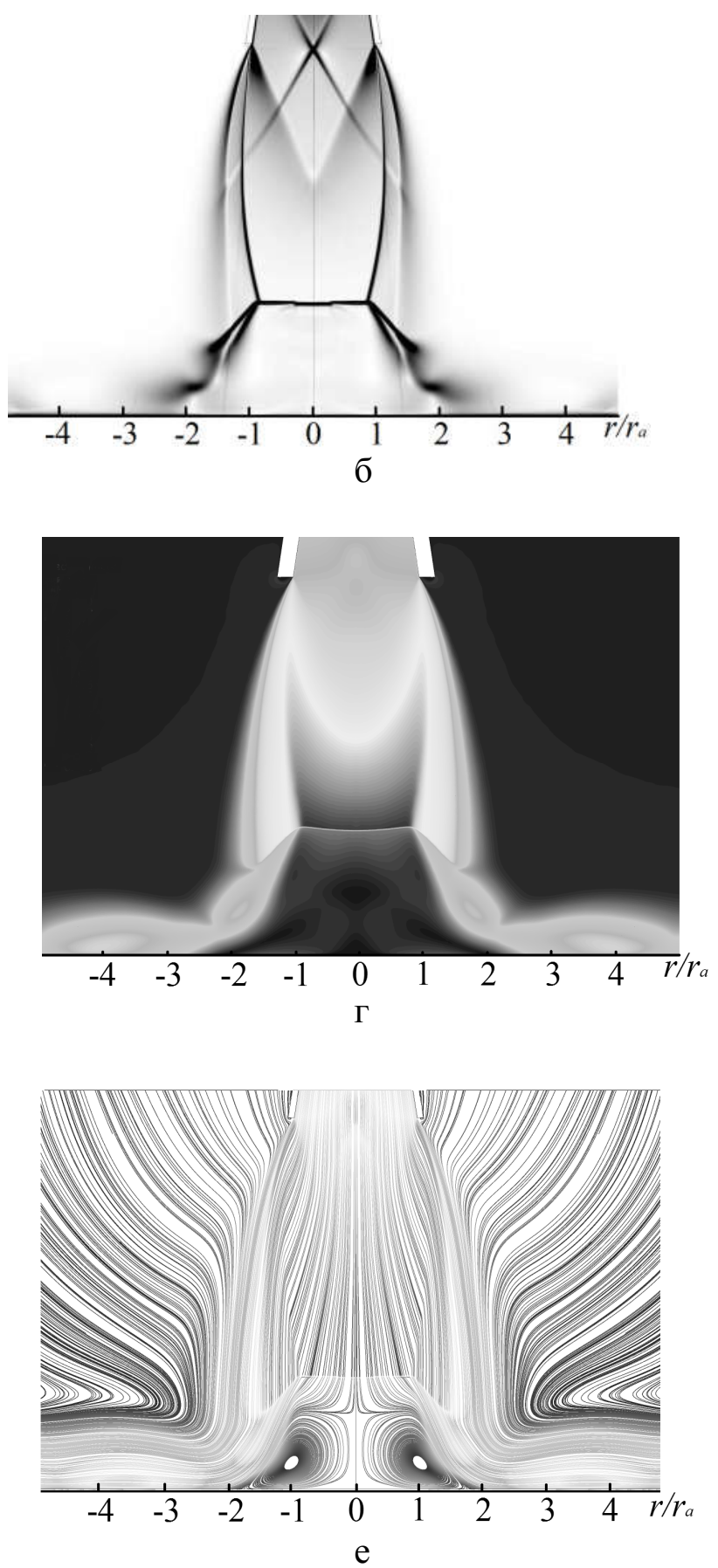

Рис. 4. Газодинамические параметры для случая $l=6 R$ :

$\mathrm{a}$ - экспериментальная визуализация (шлирен-фотография) картины течения; б - градиент плотности; в - коэффициент давления на пластине (сплошная линия - численный расчет, круги - эксперимент); г - числа Маха; д - коэффициент трения на пластине; е - линии тока. 

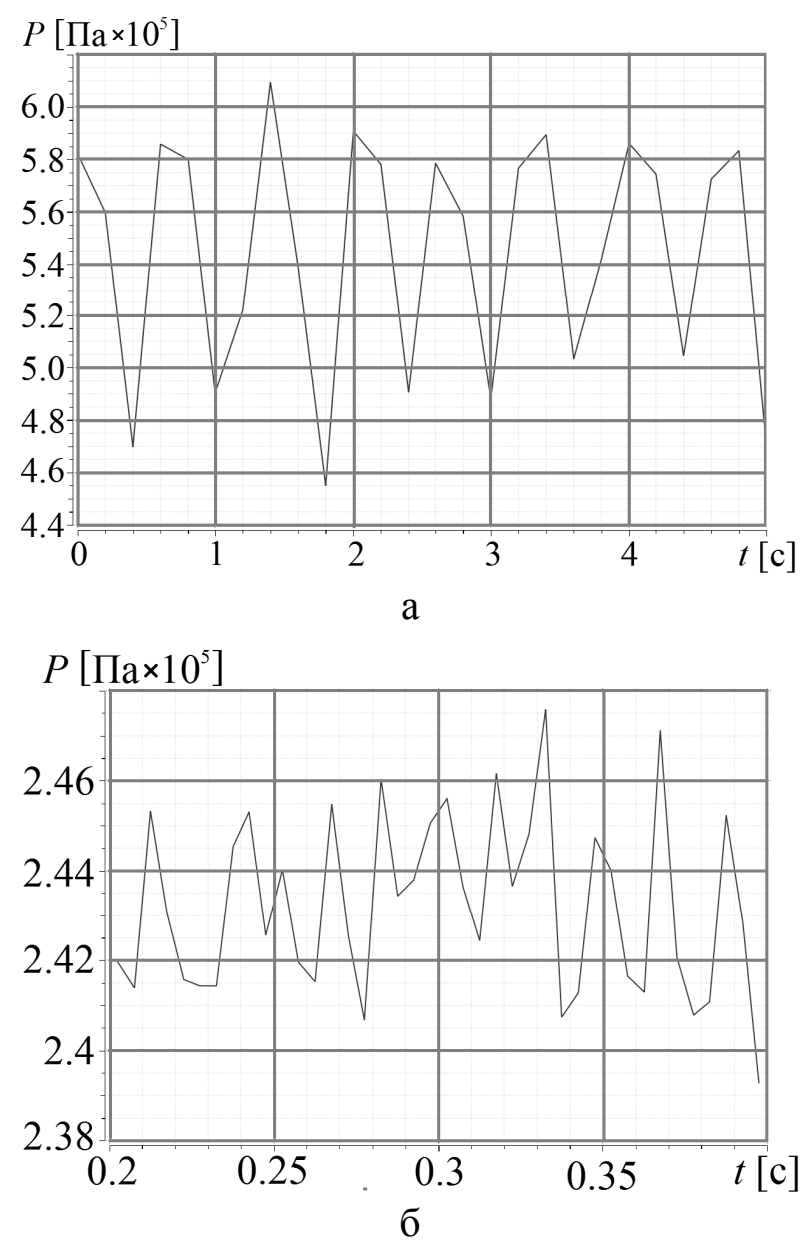

$P\left[\Pi a \times 10^{6}\right]$

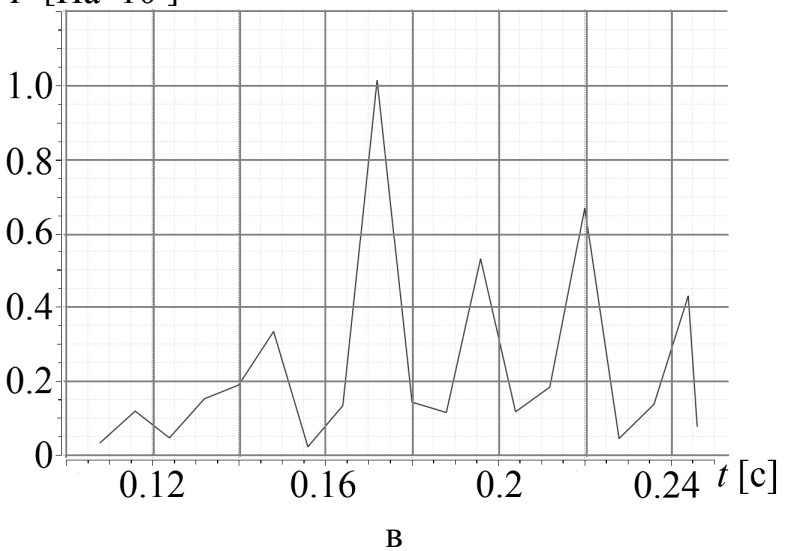

Рис. 5. Представление колебательного процесса: $\mathrm{a}-$ для случая $l=2 R ;$ б - для случая $l=4 R ;$ в - для случая $l=6 R$

Исследовано влияние расстояния от среза сопла до преграды на структуру течения и распределение газодинамических параметров. Результаты расчетов представлены в виде распределения числа Маха и градиента плотности в расчетной области, а также коэффициентов давления и трения по поверхности пластины. Выполнено сравнение результатов численного счета с экспериментальными данными.

\section{Библиографические ссылки}

1. Alvi F.S., Ladd J.A., Bower W.W. Experimental and Computational Investigation of Supersonic Impinging Jets. AIAA Journal. V. 40. 2002. P. 599-609.

2. Адрианов А.Л., Безруков А.А., Гапоненко Ю.А. Численное исследование взаимодействия сверхзвуковой струи газа с плоской преградой. Прикладная механика и техническая физика. 2000. Т. 41. № 4. С. 106-111.

3. Анцупов А.В., Благосклонов В.И., Пимштейн В.Г. Взаимодействие перерасширенной струи газа с плоской преградой. Учен. зап. ЦАГИ. 1973. Т. 4. № 1. C. $84-87$.

4. Губанова О.И., Лунев В.В., Пластинина Л.И. О центральной срывной зоне при взаимодействии сверхзвуковой недорасширенной струи с преградой. Изв. АН СССР, МЖГ. 1971. № 2. С. 135-138.

5. Дубинская Н.В., Иванов М.Я. К расчету взаимодействия сверхзвуковой струи идеального газа с плоской преградой, перпендикулярной ее оси. Учен. зап. ЦАГИ. 1975. Т. 6. № 5. С. 38-44.

6. Кудимов Н.Ф., Сафронов А.В., Третьякова О.Н. Численное моделирование взаимодействия многоблочных сверхзвуковых турбулентных струй с преградой. Электронный журнал «Труды МАИ». 2013. Вып. № 70. С. 30-43.

7. Мельникова М.Ф., Нестеров Ю.Н. Воздействие сверхзвуковой нерасчетной струи на плоскую преграду, перпендикулярную оси струи. Учен. зап. ЦАГИ. 1971. Т. № 5. С. 105-108.

8. Набережнова Г.В., Нестеров Ю.Н. Неустойчивое течение в области взаимодействия недорасширенной струи с преградой. Учен. зап. ЦАГИ. 1982. Т. 13. № 4. C. 134-140.

Надійшла до редколегії 01.06.2018 p. 